\title{
Bacillary angiomatosis in an HIV-positive man with multiple risk factors: A clinical and epidemiological puzzle
}

\author{
Farrah J Mateen $\mathrm{MD}^{1}$, Jill C Newstead MD², Karen L McClean MD FRCPC ${ }^{3}$
}

\begin{abstract}
FJ Mateen, JC Newstead, KL McClean. Bacillary angiomatosis in an HIV-positive man with multiple risk factors: A clinical and epidemiological puzzle. Can J Infect Dis Med Microbiol 2005;16(4):249-252.
\end{abstract}

A 36-year-old man with advanced AIDS presented with skin lesions, fever and weight loss. Physical examination revealed skin lesions suggestive of bacillary angiomatosis. Diagnostic imaging identified bone lesions, soft tissue masses and a single hepatic lesion. His clinical presentation was most consistent with Bartonella quintana; however, his risk for infection with B quintana was limited to a remote, brief period of homelessness. In contrast, his frequent contact with cats presented substantial potential exposure to Bartonella henselae.

Diagnosing a Bartonella infection presents challenges. The detection of bacteremia is hindered by slow growth in BACTEC media (BD Diagnostic Systems, Canada). In the present case, recovery of the organism required blind subcultures after at least eight days of incubation. Speciation by 16 s ribosomal RNA analysis confirmed B quintana as the pathogen.

Because the patient presented with skin lesions, the diagnosis was straightforward; however, skin lesions are nondiagnostic in some cases. Microbiological confirmation of the diagnosis rests on sufficient clinical suspicion to apply labour-intensive laboratory protocols.

Key Words: Bacillary angiomatosis; Bartonella; HIV

36-year-old HIV-positive man presented to the emergency Aroom with a two-day history of fever, chills, cough, diarrhea and weight loss $(22.5 \mathrm{~kg})$ over the preceding 12 months. He was noted to have widespread polymorphic skin lesions and focal areas of soft tissue swelling (Figure 1). The most striking cutaneous lesion was a friable exophytic mass, $2 \mathrm{~cm}$ to $2.5 \mathrm{~cm}$ in diameter, located in the left region of the neck (Figure 2).

He was a known intravenous drug and cocaine user, with over 100 lifetime female sexual partners. He had previously been documented as seropositive to HIV and hepatitis B and C. At his initial assessment for HIV infection, his $\mathrm{CD}_{4}$ cell count was $621 \times 10^{6} / \mathrm{L}(32.7 \%)$, and he was p24 antigennegative. Following this assessment, he was lost to follow-up and received no HIV care until he presented to the emergency

\section{Angiomatose bacillaire chez un homme séropositif à l'égard du VIH et présentant plusieurs facteurs de risque : énigme clinique et épidémiologique}

Un homme de 36 ans, rendu à un stade avancé du sida, a consulté pour des lésions cutanées, de la fièvre et une perte de poids. L'examen physique a révélé la présence de lésions qui laissaient penser à une angiomatose bacillaire. L'imagerie de diagnostic a montré des lésions osseuses, des masses de tissus mous et une seule lésion hépatique. Le tableau clinique était surtout compatible avec Bartonella quintana; toutefois, son risque d'infection à ce micro-organisme se limitait à une courte période éloignée de sans-abrisme. Par contre, ses nombreux contacts avec les chats augmentaient sensiblement son exposition à Bartonella henselae.

Diagnostiquer une infection à Bartonella n'est pas une mince affaire. La détection de la bactériémie est entravée par la croissance lente du bacille dans les milieux BACTEC (BD Diagnostic Systems, Canada). Dans le présent cas, la récupération du micro-organisme a nécessité des souscultures en aveugle après au moins huit jours d'incubation. La différenciation des espèces par l'analyse de l'ARN ribosomique $16 \mathrm{~S}$ a permis d'identifier l'agent pathogène comme B. quintana.

Comme le patient présentait des lésions cutanées, le diagnostic a été sans appel. Toutefois, les lésions cutanées n'ont pas toujours une valeur diagnostique. La confirmation microbiologique du diagnostic repose sur une présomption clinique suffisamment forte pour justifier l'application de protocoles de laboratoire, exigeants en main-d'œuvre.

room five years later. Six years before this presentation, he had briefly lived in a homeless shelter in British Columbia. He had recent, significant household contact with young kittens.

On examination, he was febrile $\left(38.2^{\circ} \mathrm{C}\right)$ with a pulse of 114 beats/min and a blood pressure of 124/73 $\mathrm{mmHg}$. He had innumerable, widespread, macronodular skin lesions that were heterogeneous in size, texture and colour. Multiple, diffuse $1 \mathrm{~cm}$ subcutaneous masses, with and without associated dusky erythema of the overlying skin, were also present, particularly over the chest wall. An exquisitely tender mass was present over the left second rib at the costochondral junction. The right wrist was swollen and tender along the ulnar border, with an overlying dusky erythema of the skin. There was striking

${ }^{1}$ College of Medicine; ${ }^{2}$ Department of Medicine; ${ }^{3}$ Division of Infectious Diseases, Department of Internal Medicine, University of Saskatchewan,

Saskatoon, Saskatchewan

Correspondence and reprints: Dr Karen L McClean, Royal University Hospital, Division of Infectious Diseases, 103 Hospital Drive, Saskatoon,

Saskatchewan S7N OW8. Telephone 306-655-1777, fax 306-975-0383, e-mail karen.mcclean@usask.ca

Received and accepted for publication January 10, 2005 


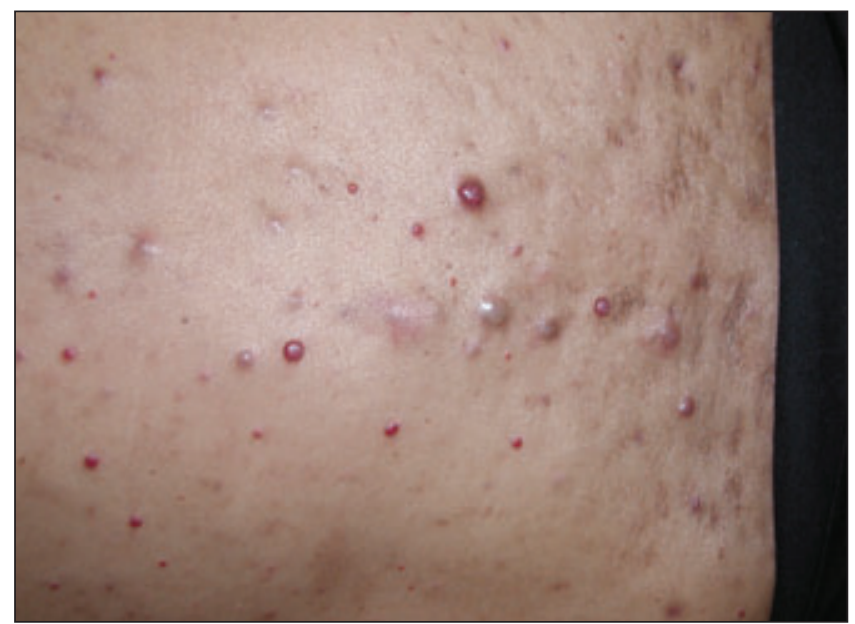

Figure 1) Small, cherry angiomata-like lesions and nodules on trunk

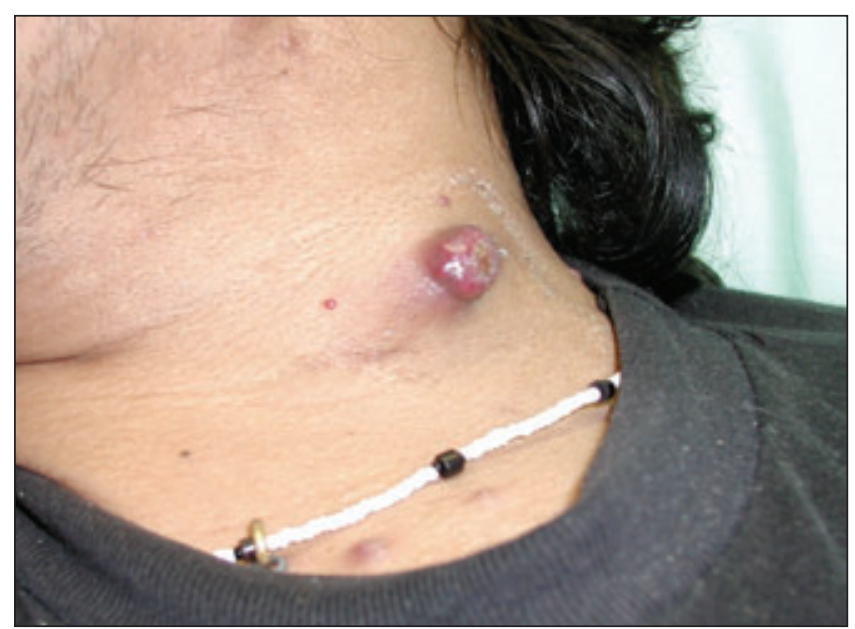

Figure 2) Exophytic lesion on neck

bilateral epitrochlear lymphadenopathy, most prominent on the right side.

Bibasilar crackles and right upper quadrant tenderness were noted. Hepatosplenomegaly was not detected. Oral thrush, oral hairy leukoplakia and genital warts were identified, but the remainder of his physical examination was unremarkable.

Laboratory tests showed microcytic, hypochromic anemia (hemoglobin $67 \mathrm{~g} / \mathrm{L}$ ) and mild absolute lymphopenia with a total white blood cell count of $2.5 \times 10^{9} / \mathrm{L}$. His $\mathrm{CD}_{4}$ cell count was $25 \times 10^{6} / \mathrm{L}(6.2 \%)$, with an HIV viral load of $1.1 \times 10^{6}$ copies $/ \mathrm{mL}$. He had mild transaminitis (alanine aminotransferase and aspartate aminotransferase levels of 1.5 times the upper limit of normal or less), and a normal alkaline phosphatase level. His erythrocyte sedimentation rate was $125 \mathrm{~mm} / \mathrm{h}$.

Plain $\mathrm{x}$-rays and a computed tomography $(\mathrm{CT})$ scan of the right wrist (Figure 3A) showed an expansile, radiolucent mass in the distal head of the ulna, with destruction of the overlying cortex, in keeping with the tender mass noted on physical examination. Radiological differential diagnosis included giant cell tumour or lytic metastatic deposit. An ultrasound of the chest wall revealed a mushroom-shaped soft tissue mass eroding the second left rib (Figure 4). A CT scan showed only a small destructive lesion of the anterior cortex of the rib; the

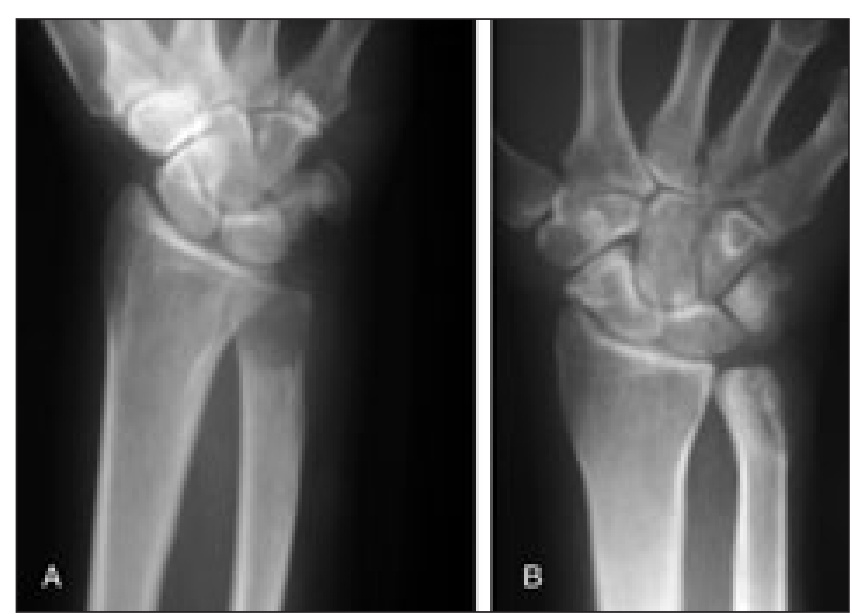

Figure 3) Radiograph of right wrist showing radiolucent mass in distal ulna at diagnosis (A) and substantial healing after one month of therapy (B)

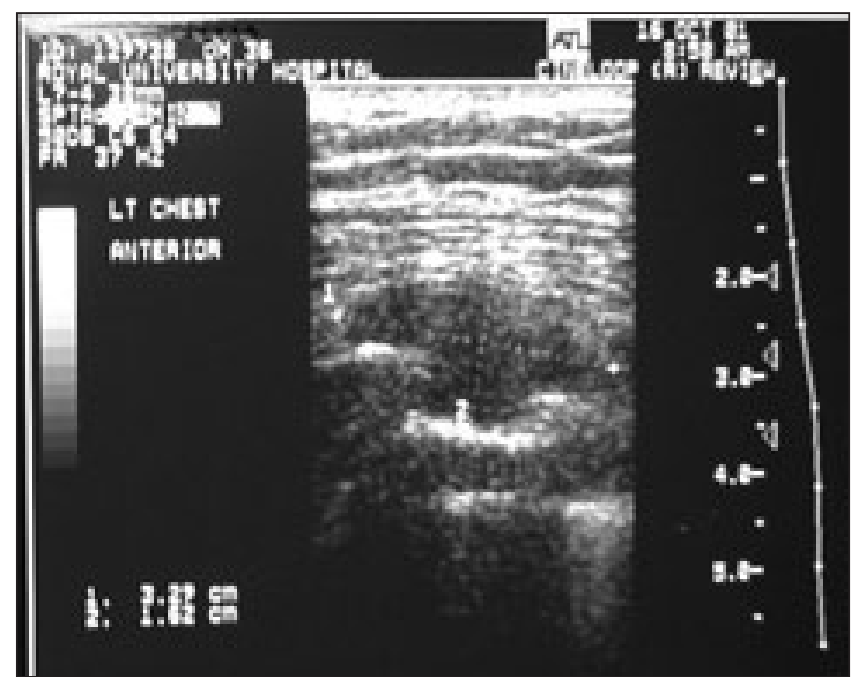

Figure 4) Ultrasound of the second left rib showing soft tissue mass and disruption of the rib cortex

soft tissue component of the lesion was not clearly visualized. Liver ultrasound demonstrated a single hypodense lesion, approximately $1 \mathrm{~cm} \times 1.5 \mathrm{~cm}$, which was not detected by CT scan (Figure 5).

A biopsy of a skin lesion revealed the presence of faintly staining Gram-negative bacilli. Histological examination of the tissue revealed marked edema of the dermis and the proliferation of small blood vessels with occasional spindle cells and neutrophil deposits. Periodic acid-Schiff and silver stains were negative for fungi. Warthin-Starry silver staining confirmed the presence of bacilli consistent with the clinical impression of bacillary angiomatosis (BA). An examination of tissue by electron microscopy revealed numerous interstitial bacilli with trilaminar cell walls (Figure 6).

Multiple blood cultures were flagged as positive by the BACTEC 9240 noninvasive fluorescent detection system (BD Diagnostic Systems, Canada) between days 6 and 16. None of the bottles flagged within the standard incubation period, and all of them would have been discarded if routine procedures had been followed. Some cultures, which later proved to be positive on blind subculture, never flagged positive. Organisms could not be visualized by Gram stain on any of the bottles that 


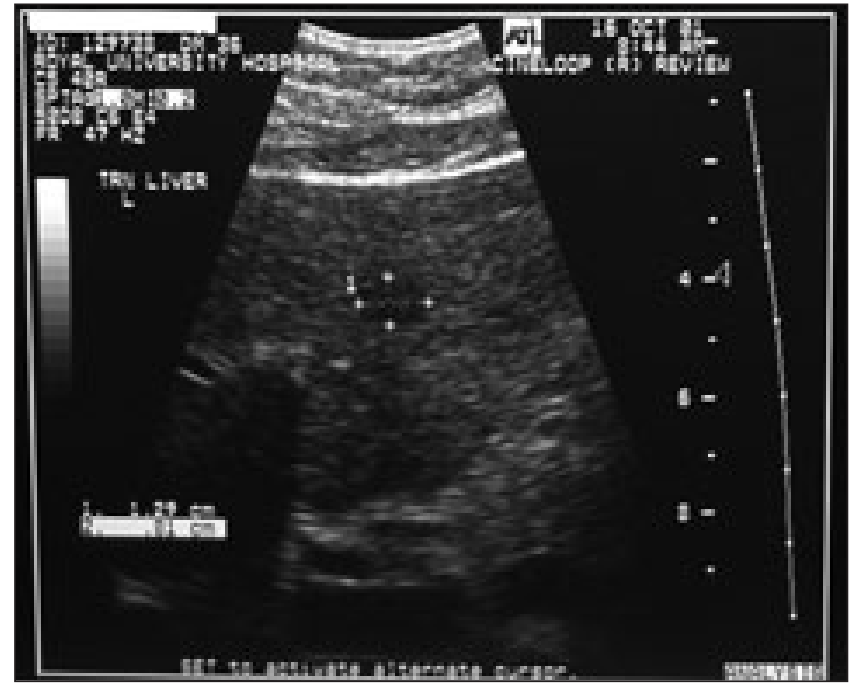

Figure 5) Ultrasound of liver showing single hypodense lesion

flagged positive. Acridine orange staining, which has been reported to improve detection (1), was not performed. Blind subcultures to Columbia blood agar (PML Microbiologicals, Canada) and chocolate agar were carried out on days 5, 13 and 21. None of the day 5 subcultures yielded growth, but subcultures on days 13 and 21 yielded pinpoint grey colonies after four to 18 days. Subcultures were also performed when bottles flagged positive and typically yielded visible colonies more quickly than blind subcultures. Organisms were recovered from aerobic and resin vials most consistently. Organisms were not recovered from Myco F Lytic bottles (BD Diagnostic Systems). Gram stains from colonies on solid media yielded faintly staining, tiny and slightly curved Gram-negative coccobacilli. In all, six of eight separate cultures over eight days were positive, including cultures up to five days after initiating therapy, beyond which no further cultures were obtained.

Although the clinical picture appeared to be more consistent with Bartonella quintana (presence of subcutaneous lesions and lytic bone lesions), the epidemiological characteristics were more suspicious for Bartonella henselae (recent extensive cat contact). Thus, the isolate was sent for 16 s ribosomal RNA analysis, which showed $99 \%$ homology to B quintana.

Based on the results of the skin biopsy, the patient was started on oral doxycycline $100 \mathrm{mg}$ twice daily, along with cotrimoxazole and azithromycin as prophylaxis for Pneumocystis and Mycobacterium avium complex, respectively. Improvement of the skin lesions was noted by day 10. Substantial healing of the lytic ulnar lesion was radiologically evident by one month (Figure 3B). Once his systemic symptoms subsided (by the third week of therapy), he was started on antiretroviral therapy with didanosine, stavudine and nelfinavir. He was followed for 19 months with no evidence of recurrence, but was subsequently lost to follow-up. He continued to take doxycycline until his last follow-up appointment.

\section{DISCUSSION}

BA and bacillary peliosis, both characterized by proliferative vascular lesions and first identified in patients with AIDS, were described by Stoler et al (2) in 1983 and Perkocha et al (3) in 1990, respectively; however, diseases caused by Bartonella species have been recognized since the preColumbian era in the form of verruga peruana, the chronic,

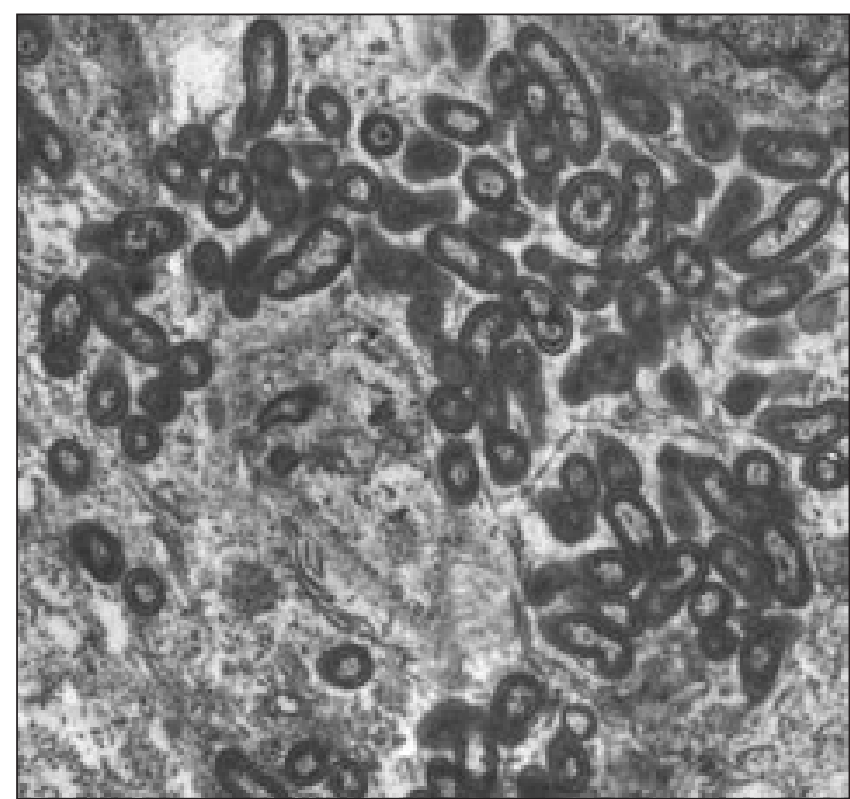

Figure 6) Electron micrograph (skin biopsy) of interstitial bacilli with trilaminar cell walls (Photograph reproduced with permission from Dr Rani Kanthan)

cutaneous stage of infection with Bartonella bacilliformis. In 1885, a Peruvian medical student by the name of Daniel Carrión demonstrated the link between the chronic stage and the acute hematogenous stage characterized by fever, anemia and transient immunosuppression (Oroya fever). Bartonella infections have been recognized in the form of 'trench fever' since World War One; however, these infections may have been described as early as the middle ages (4).

Bartonella is the only bacterial genus known to cause cutaneous angioproliferation (5). Of the 14 species identified, five are known to cause disease in humans and only two - B quintana and B henselae - have been associated with BA (6). The spectrum of disease caused by the Bartonella genus includes endocarditis, trench fever, Oroya fever, Carrión's disease, catscratch disease and chronic lymphadenopathy, as well as neurological disorders such as meningoencephalitis and focal central nervous system lesions.

Proliferative lesions of the vasculature are prominent in BA, most commonly involving the skin and presenting as highly polymorphic skin lesions ranging from papules to pedunculated nodules (6). The major differential diagnosis for cutaneous lesions of BA is Kaposi's sarcoma. Focal lesions may present in many other tissues, including bone, brain, lymph nodes, respiratory tract, cardiac valves, gastrointestinal tract and bone marrow (7). Bone lesions typically involve the long bones and produce painful lytic lesions, sometimes with overlying skin changes (as in the present patient). Radiological features include well-circumscribed osteolysis with or without associated periostitis (7). Bacillary peliosis refers to proliferative vascular lesions of the liver and spleen, characterized by blood-filled spaces with bacillary clusters and a fibromyxoid stroma (3). Hepatomegaly, elevated alkaline phosphatase levels and parenchymal heterogeneity of the liver and spleen (with low-density lesions on ultrasound or CT) are characteristic features (7).

A case-control study by Koehler et al (8) suggested that while both $B$ henselae and $B$ quintana typically cause skin 
lesions, subcutaneous masses and bone lesions are more likely to be due to $B$ quintana, and bacillary peliosis and lymph node involvement are more likely to be due to $B$ henselae. The present patient had several bone lesions and subcutaneous masses with a single hypodense, well-circumscribed hepatic lesion on ultrasound without hepatomegaly. This lesion, if due to Bartonella infection, likely reflects the lesser propensity for $B$ quintana to cause hepatic lesions. Because the patient was lost to follow-up before a repeat ultrasound could be performed, we were unable to determine if resolution had occurred with doxycycline therapy.

AIDS patients with $\mathrm{CD}_{4}$ cell counts of less than $100 \times 10^{6}$ cells/L are at increased risk of infection due to Bartonella species (6). Fever caused by Bartonella species is likely under-recognized (9), particularly if skin lesions are absent or few, and the presentation is nonspecific. As a treatable cause of fever, the recognition of risk for Bartonella infection in immunocompromised hosts is critical to convey appropriate information to the microbiology laboratory. As the present case highlights, standard incubation periods (five days) for blood cultures are inadequate to detect Bartonella species. Slow carbon dioxide generation may result in inconsistent flagging of culture bottles. Even when cultures flag positive, organisms may not be visualized on Gram stain.

Clinical suspicion of Bartonella mandates prolonged incubation in a carbon dioxide-rich environment with increased humidity $(40 \%)$ for up to six weeks $(1,10)$. Blind subcultures may improve the detection of bacteremia; in the present case, however, no subcultures performed before day 9 yielded detectable growth on solid media, and subcultures taken after a bottle had flagged positive yielded growth more quickly than blind subcultures. Although extended incubation is not technically demanding, the enriched medium and relatively lengthened culture time may heighten the risk of fungal or bacterial contamination of samples $(1,10)$.

\section{REFERENCES}

1. Maurin M, Birtles R, Raoult D. Current knowledge of Bartonella species. Eur J Clin Microbiol Infect Dis 1997;16:487-506.

2. Stoler MH, Bonfiglio TA, Steigbigel RT, Pereira M. An atypical subcutaneous infection associated with acquired immune deficiency syndrome. Am J Clin Pathol 1983;80:714-8

3. Perkocha LA, Geaghan SM, Yen TS, et al. Clinical and pathological features of bacillary peliosis hepatis in association with human immunodeficiency virus infection. N Engl J Med 1990;323:1581-6.

4. Kostrzewski J. The epidemiology of trench fever. Bull Acad Pol Sci (Med) 1949;7:233-63

5. Velho PE, Cintra ML, Uthida-Tanaka AM, de Moraes AM, Mariotto A. What do we (not) know about the human bartonelloses? Braz J Infect Dis 2003;7:1-6.
Whereas B henselae is known to have a reservoir in cats and involves transdermal inoculation of bacteria after close contact, the reservoir for $B$ quintana remains uncertain $(1,6)$. Homelessness, poverty and alcoholism are recognized risk factors for B quintana infection, and unsanitary living conditions may predispose to ectoparasites that transmit the infection among those at risk (11).

The present patient had clinical and epidemiological clues pointing to both $B$ quintana and B henselae. While B quintana is more commonly associated with lytic bone lesions and a history of homelessness, B henselae is suggested by a greater incidence of bacillary peliosis and exposure to cats. 16s ribosomal RNA analysis allowed for the confirmation of B quintana as the cause of $\mathrm{BA}$ in the present patient despite the fact that, epidemiologically, his risk for $B$ henselae seemed greater and more recent. While speciation did not affect chemotherapeutic decisions, it encouraged us to defer recommended surgical intervention for the ulnar lesion (en bloc resection of the distal third of the ulna for possible aggressive bone tumour) until we could observe a response to therapy. A prompt response allowed the patient to avoid unnecessary surgery.

The present case also highlights the potential for persistence of bacteremia for prolonged periods, even after the initiation of therapy. Bacteremia persisted for at least five days after therapy began and likely longer, as high-grade fevers continued for several weeks; however, no further blood cultures were obtained. Despite the prolonged bacteremia, the cutaneous and bone lesions showed a prompt improvement, with regression of skin lesions evident within 10 days and sclerosis of the lytic lesion within a month.

Bartonella is an infrequent but important pathogen in immunocompromised patients. While easily treated, infection due to Bartonella may be clinically unrecognized if characteristic skin lesions are absent or overlooked, and microbiologically unrecognized if appropriate protocols are not followed.

6. Maguina C, Gotuzzo E. Bartonellosis. New and old. Infect Dis Clin North Am 2000;14:1-22.

7. Koehler JE, Tappero JW. Bacillary angiomatosis and bacillary peliosis in patients infected with human immunodeficiency virus. Clin Infect Dis 1993;17:612-24.

8. Koehler JE, Sanchez MA, Garrido CS, et al. Molecular epidemiology of bartonella infections in patients with bacillary angiomatosispeliosis. N Engl J Med 1997;337:1876-83.

9. Koehler JE, Sanchez MA, Tye S, et al. Prevalence of Bartonella infection among human immunodeficiency virus-infected patients with fever. Clin Infect Dis 2003;37:559-66.

10. Anderson BE, Neuman MA. Bartonella spp. as emerging human pathogens. Clin Microbiol Rev 1997;10:203-19.

11. Ohl ME, Spach DH. Bartonella quintana and urban trench fever. Clin Infect Dis 2000;31:131-5. 


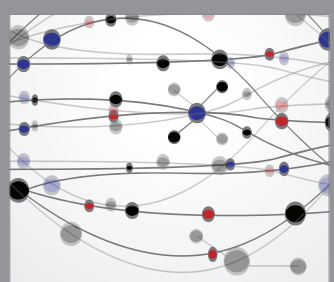

The Scientific World Journal
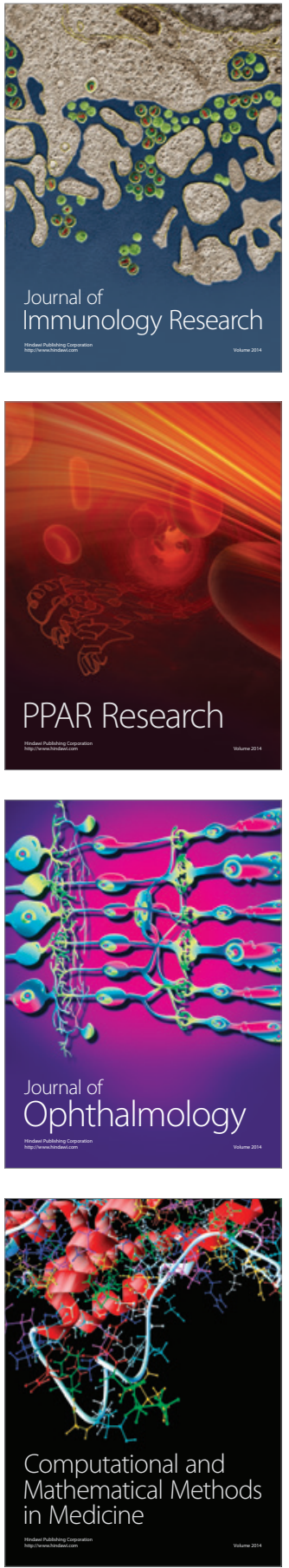

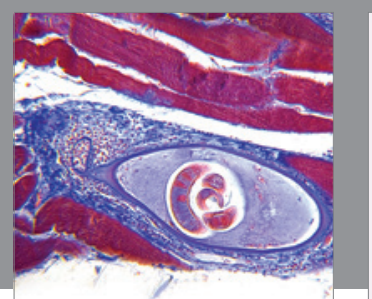

Gastroenterology Research and Practice

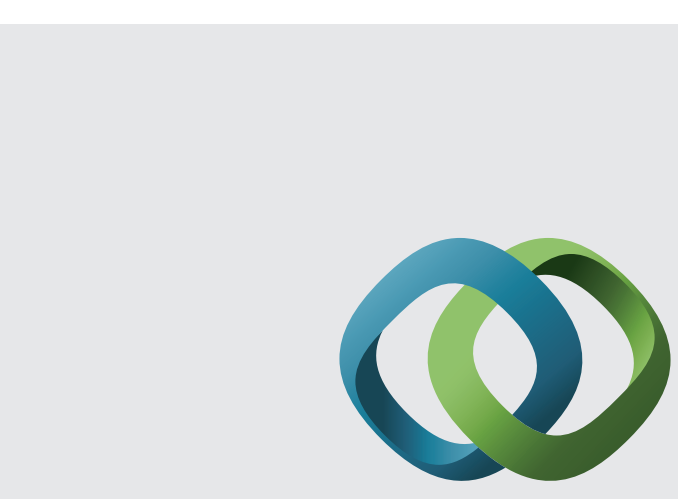

\section{Hindawi}

Submit your manuscripts at

http://www.hindawi.com
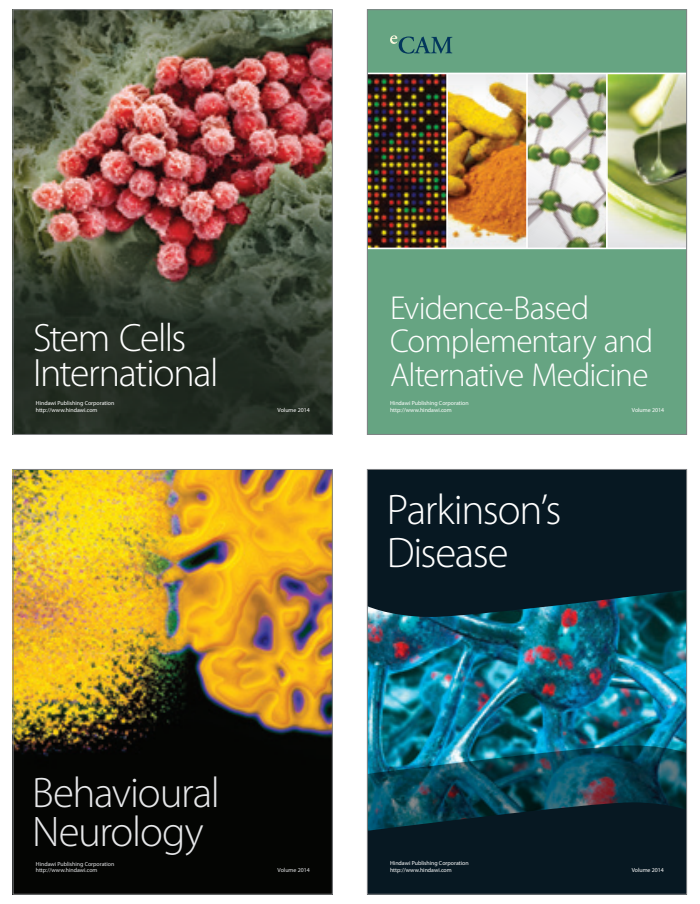
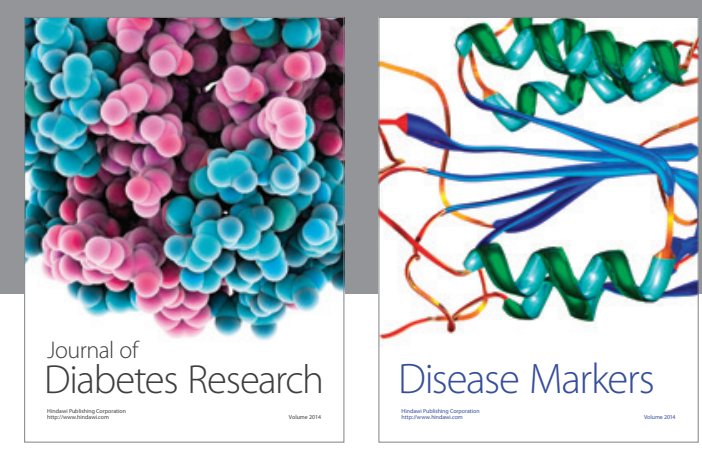

Disease Markers
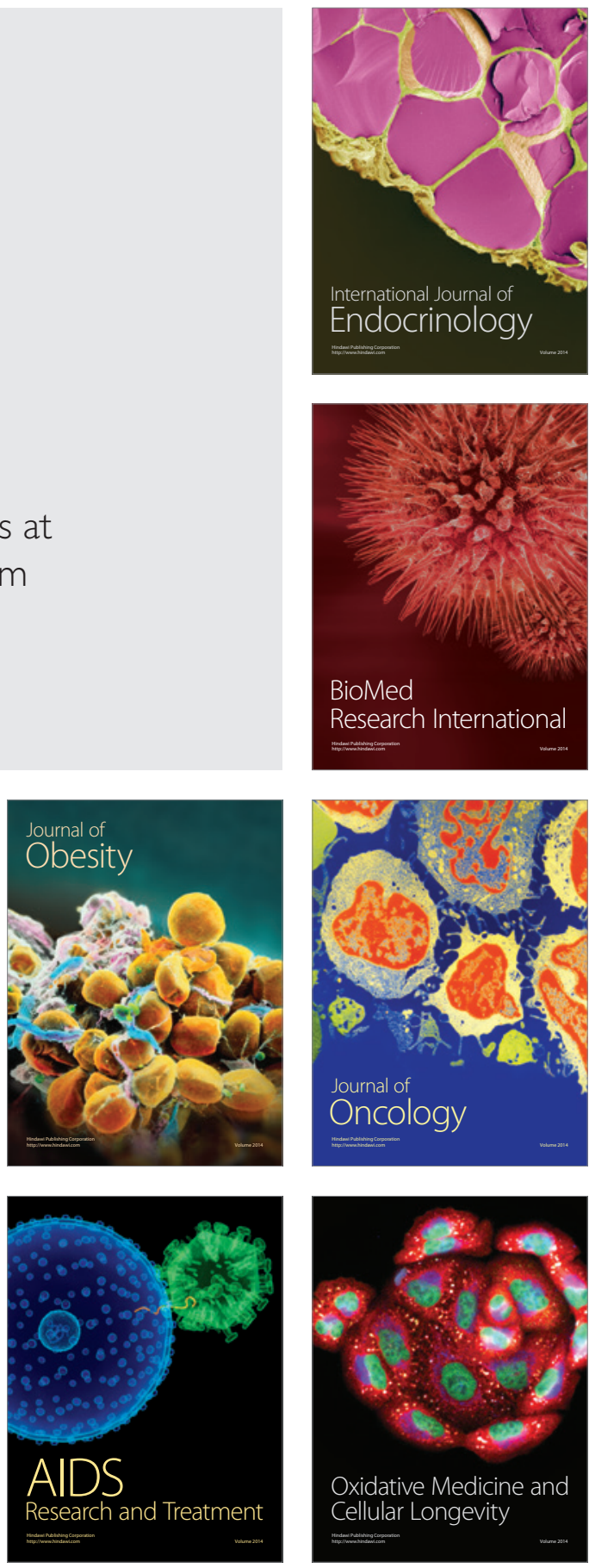